\title{
O PRESIDENCIALISMO DE COALIZÃO E O IMPEACHMENT DE 2016: UMA LEITURA A PARTIR DA PEC 21/2015 PARA A IMPLANTAÇÃO DO RECALL NO BRASIL
}

\author{
THE COALITION PRESIDENTIALISM AND THE IMPEACHMENT OF 2016: A READING \\ FROM PEC 21/2015 FOR THE IMPLANTATION OF THE RECALL IN BRAZIL
}

\begin{abstract}
Nina Tricia Disconzi Rodrigues
Professora adjunta no Departamento de Direito na Universidade Federal de Santa Maria e no programa de PósGraduação em Direito da UFSM (Mestrado), lecionando a disciplina Democracia na Sociedade em Rede. Doutora em Direito do Estado, pela Universidade de São Paulo USP. Coordenadora do Grupo de Pesquisa, cadastrado no CNPQ, Grupo de Pesquisa em Direito dos Animais, denominado GPDA, da Universidade Federal de Santa Maria. Vice-líder do Grupo de Pesquisa cadastrado no CNPq, denominado CEPEDI - Centro de Estudos e Pesquisas em Direito e Internet da Universidade Federal de Santa Maria. E-mail: ninadisconzi@uol.com.br
\end{abstract}

\section{Lucas Mateus Canabarro Rodrigues}

Mestrando em Direito pelo Programa de Pós-Graduação em Direito da Universidade Federal de Santa Maria PPGD/UFSM. Bolsista da Coordenação de Aperfeiçoamento de Pessoal de Nível Superior - CAPES. Graduado em Direito pela Faculdade Metodista de Santa Maria - FAMES. Pesquisador do Centro de Estudos e Pesquisas em Direito e Internet da Universidade Federal de Santa Maria (CEPEDI). E-mail: lucasmcrodrigues@gmail.com

Recebido em: 18/02/2019

Aprovado em: 01/09/2020

RESUMO: O presente trabalho versa sobre os impasses do denominado presidencialismo de coalizão no Brasil e os desafios para implantação do instituto do Recall no ordenamento jurídico pátrio a partir de uma leitura do processo de impeachment ocorrido no ano de 2016. Para tanto se optou por dividir este artigo em duas partes: 1) Os impasses do presidencialismo de coalizão no Brasil e o impeachment de 2016, no qual se aborda o instituto do presidencialismo no Brasil e sua morfologia eleitoral complexa, que resultou no chamado presidencialismo de coalizão com forte tensão nas relações entre o Presidente da República e sua base de apoio no Congresso Nacional e; 2) A necessidade de aprimoramento da democracia participativa no Brasil: a proposta de recall do Presidente da República de acordo com a PEC 21/2015, na qual busca-se analisar a proposta de emenda à Constituição que pretende implantar no Brasil o recall. Para tanto, utilizou-se do método de pesquisa dedutivo, valendo-se das premissas maiores para formação das premissas menores.

Palavras-chave: Presidencialismo de Coalizão. Impeachment de 2016. Democracia Participativa. Reccal. PEC 21/2015 do Senado Federal.

ABSTRACT: This paper deals with the impasses of so-called coalition presidentialism in Brazil and the challenges of implementing the Recall institute in the country's legal system based on a 
reading from the impeachment process that took place in the year 2016. For this purpose, this article in two chapters: 1) The impasses of coalition presidentialism in Brazil and the impeachment of 2016, which addresses the institute of presidentialism in Brazil and its complex electoral morphology that resulted in so-called coalition presidentialism with strong tension in relations between the President of the Republic and his base of support in the National Congress and; 2) The need to improve participatory democracy in Brazil: the recall proposal of the President of the Republic in PEC 21/2015, which outlines the proposed amendment to the constitution of the Federal Senate to implement the legal institute of recall in Brazil. For this purpose, the deductive research method was used, using the larger assumptions for the formation of the smaller premises.

Keywords: Coalition Presidentialism. Impeachment of 2016. Participative Democracy. Recall. PEC 21/2015 of the Federal Senate.

SUMÁRIO: Introdução. 1 Os impasses do presidencialismo de coalizão no Brasil e o impeachment de 2016. 2 A necessidade de aprimoramento da democracia participativa no Brasil: A proposta de recall do Presidente da República na PEC 21/2015. Considerações Finais. Referências.

\section{INTRODUÇÃO}

Nos últimos anos, o Brasil vem sendo marcado por um cenário de forte instabilidade política, para demonstrar essa problemática, registre-se o fato do impeachment da Presidente Dilma Roussef em 2016 e a impopularidade do Vice-Presidente Michel Temer ao assumir o cargo no mesmo ano, denunciado perante o Supremo Tribunal Federal e com alto índice de rejeição entre os eleitores. Tal conjuntura no Poder Executivo vem gerando um "efeito dominó", ocasionando instabilidade nos outros poderes e reflexos que atingem toda a nação, especialmente a crise econômica atual, aumento das desigualdades sociais e um decurso de retrocesso em direitos sociais. Para piorar, vivenciamos a realidade de um Poder Legislativo fragmentado no panorama institucional brasileiro, o qual designa sua agenda legislativa em forte dependência ao Poder Executivo.

Essa situação é reflexo do hiperpresidencialismo ${ }^{1}$ que detém uma excessiva atribuição de poderes na figura do Presidente da República, fator perceptível também em outros países da América-latina que passaram recentemente por ditaduras militares. Uma das consequências do hiperpresidencialismo é a chamada "democracia delegativa"2 na qual o Presidente da República é a encarnação viva da vontade da nação. Pode esse fenômeno ser considerado um impasse institucional? Qual o instrumento disponível ao povo para retirar o Presidente eleito que não representa mais a vontade dos que o elegeram? Quais os mecanismos de controle da responsabilidade política?

Resultado desse processo no Brasil é a importação de um sistema presidencialista inspirado no modelo dos Estados Unidos, porém seriamente distorcido nos dias atuais. Enquanto o modelo americano é baseado logicamente na divisão de poder entre o Presidente da República, o Legislativo e o Judiciário; aqui no Brasil se tem um excesso de expectativa e concentração de

\footnotetext{
${ }^{1}$ Outros autores também tratam como "Presidentismo", termo cunhado por Sérgio Resende de Barros para definir a lógica do presidencialismo brasileiro. Já o constitucionalista Sérgio Abranches desenvolveu a nomenclatura "Presidencialismo de Coalizão". Neste trabalho utiliza-se o termo "hiperpresidencialismo" baseado na nomenclatura do Pesquisador Roberto Gargarella, o qual define este termo para caracterizar o padrão de presidencialismo presente não apenas no Brasil, mas também em outros países da América Latina os quais passaram por processos de ditadura militar e após sua democratização mantiveram um excesso de atribuições nas mãos do chefe do Poder Executivo.

2 O termo "Democracia Delegativa" é cunhado por O"e Donnell (1991, p.25) o qual refere que a democracia delegativa é fortemente individualista, uma espécie de "vale tudo" no qual o candidato que vence a eleição presidencial é autorizado a governar como lhe parece conveniente, independente de vinculação partidária ou ideológica.
}

Revista de Direito Brasileira | Florianópolis, SC | v. 26 | n. 10 | p. 144-160 | Mai./Ago. 2020 
atribuições baseadas unicamente na figura do Presidente da República e um Legislativo enfraquecido.

Diante de tal problemática insurge-se o questionamento de como repensar o hiperpresidencialismo brasileiro a partir do aprimoramento da democracia participativa no Brasil, especialmente através da figura do recall do mandatário do Poder Executivo, como um mecanismo de controle sobre atos de irresponsabilidade política. Para tanto, elegeu-se a PEC 21/2015 do Senado Federal enquanto proposta de implantação de tal instituto no Brasil, uma vez que já foi aprovada perante a Comissão de Constituição e Justiça - CCJ e está apta a ser deliberada em plenário.

A análise do tema proposto deu-se a partir do método de abordagem dedutivo, que, partindo das teorias e leis, na maioria das vezes prediz a ocorrência dos fenômenos particulares, conexão descendente (LAKATOS; MARCONI, 1999). A pesquisa versará sobre o modelo de presidencialismo efetivado e os impasses para sua eficiência no Brasil. Em um segundo tópico, será abordado o instituto jurídico-constitucional do recall, sua utilização nos Estados Unidos da América e a proposta para implementá-lo no Brasil por meio de proposta de emenda à constituição originária do Senado Federal.

\section{OS IMPASSES DO PRESIDENCIALISMO DE COALIZÃO NO BRASIL E O IMPEACHMENT DE 2016}

A Constituição Federal de 1988 no seu artigo primeiro estabelece que "a República Federativa do Brasil constitui-se em Estado Democrático de Direito" determinando no parágrafo único que "todo o poder emana do povo, que o exerce por meio de representantes eleitos ou diretamente, nos termos desta Constituição". Logo, se está vivendo num país democrático, onde o povo exerce seu poder por meio de seus representantes genuinamente eleitos. Portanto se elege no Brasil a democracia representativa e a democracia participativa como formas de participação política dos cidadãos.

Para Silva (2014, p.147-148) a Constituição de 1988 optou por uma democracia representativa e, em alguns casos uma democracia direta, conforme se depreende de uma rápida passagem de uma das suas obras:

Os constituintes optaram por um modelo de democracia representativa que tem como sujeitos principais os partidos políticos, que vão ser os protagonistas quase exclusivos do jogo político, com temperos de princípios e institutos de participação direta dos cidadãos no processo decisório governamental. Daí decorre que o regime assume uma forma de democracia participativa, no qual encontramos participação por via representativa (mediante representantes eleitos através de partidos políticos, arts. $1^{\circ}$, parágrafo único, 14 e 17; associações, art. $5^{\circ}$ XXI; sindicatos, art. $8^{\circ}$, III, eleição de empregados junto aos empregadores, art. 11) e participação por via direta do cidadão (exercício de poder, art. $1^{\circ}$ parágrafo único; iniciativa popular, referendo e plebiscito, já indicados).

O termo democracia precisa ser contextualizado, já que há inúmeras teorias sobre do que se trata realmente a democracia. Conceituá-la não é tarefa fácil e requer muita cautela. A palavra democracia é formada por "demos" o qual significa "povo" e "kratos", o qual significa "autoridade", portanto um governo baseado na autoridade do povo e legitimado a tomar as decisões daqueles que o representam. A democracia pode ser exercida de diferentes formas, incluindo-se a democracia representativa, direta, participativa, dentre outras ${ }^{3}$ (MENEZES, 1999, p.267). Para

\footnotetext{
${ }^{3}$ A democracia representativa é o exercício do poder da população por meio de seus representantes, eleitos para atuarem em seu nome durante um mandato. A democracia participativa significa a possibilidade de intervenção direta dos cidadãos nos procedimentos de tomada de decisão e de controle do exercício do Poder (Também chamada

Revista de Direito Brasileira | Florianópolis, SC | v. 26 | n. 10 | p. 144-160 | Mai./Ago. 2020
} 
Fleury (2006, p.94) no Brasil, como em outros países, a soberania popular é exercida primordialmente por meio da representação, obtida através de eleições para o poder executivo e legislativo.

Para Bonavides (2001, p.355) "O poder é do povo, mas o governo é dos representantes, em nome do povo: eis aí toda a verdade e essência da democracia representativa.", sendo o caminho pelo qual a população governa o Estado por meio de seus representantes, os quais são eleitos por meio do voto. E o autor vai além, asseverando que a democracia representativa tem como bases a soberania popular, o sufrágio universal, a observância à constituição, a separação dos poderes, igualdade de todos perante a lei, adesão ao princípio da fraternidade social, limitação das prerrogativas dos governantes e temporariedade dos mandatos eletivos, dentre outras. (BONAVIDES, 2001, p.294).

No Brasil, como em demais países da América-latina, adota-se o modelo presidencialista, o qual nasceu com a Constituição norte-americana de 1787, que estabeleceu um regime baseado quase que exclusivamente na figura central do Presidente da República, que acumulava funções de Chefe de Estado e de Governo. Nesse sistema o presidente da República é escolhido democraticamente $^{4}$, tendo seu cargo legitimado através dos votos dos cidadãos (BONAVIDES, 2001, p.383). Esse governo presidencialista se baseia na "separação dos poderes, o seja, na previsão de Legislativo, Executivo e Judiciário, independentes entre si, cada um com uma competência (relativamente) especializada numa das funções do Estado" (FERREIRA FILHO, 2001, p.123).

Sartori (2017, p.1) define o presidencialismo a partir da existência de pelo menos três critérios:

Primeiro, a escolha do chefe de Estado se dá mediante eleição popular (direta ou indireta) e por um período preestabelecido; segundo, o Parlamento não possui o poder de nomear nem de remover o governo; terceiro, o chefe de Estado também é o chefe do governo. [...] Isso significa que um sistema é presidencialista se e somente se (i) a escolha do chefe de Estado (presidente) resulta de eleições populares; (ii) durante o mandato preestabelecido, ele não pode ser demitido pelo voto parlamentar; e (iii) ele chefia o governo ou governos por ele próprio nomeados. Preenchidas todas essas condições, encontraremos sem dúvida um sistema presidencialista "puro".

Interessante consignar que conforme Sartori (2017, p.1) durante o mandato do Presidente da República este não pode ser demitido pelo voto parlamentar, ou seja, a responsabilidade do presidente da República é penal e não política. Ensina Bonavides (2001, p.297) que o Presidente de República responde no exercício de seu mandato por crime de responsabilidade no exercício da competência constitucional, de ordem administrativa, que lhe é atribuída. Ao contrário do parlamentarismo, quando o chefe de governo pode ser destituído por questões políticas. No presidencialismo o afastamento do Presidente da República ocorre pelo processo de impeachment, fixado os limites do crime de responsabilidade.

É de se ressaltar que entre os três poderes, o Executivo e Legislativo provêm diretamente do povo, são eleitos por este. "Eleitos diretamente por este os deputados e senadores que integram as casas do Legislativo; eleito diretamente pelo povo também o Presidente da República, que comanda o Executivo." (FERREIRA FILHO, 2001, p.193). Especialmente no caso do Presidente da República os seus poderes devem derivar da própria nação, raramente, em situações excepcionais, do Congresso por via indireta. Dessa forma, o Presidente da República recebe da

democracia deliberativa, exemplo plebiscito e referendo) e a democracia direta é o meio pelo qual os próprios cidadãos são os responsáveis pelo processo de decisão. Para mais sobre o tema consultar BONAVIDES, Paulo. Ciência Política. 10. ed. São Paulo: Malheiros, 2001.

${ }^{4}$ Nos Estados Unidos da América é adotado uma forma indireta de participação na escolha do Presidente da República, sendo escolhido por um colégio de representantes - fato que não deslegitima a escolha da população.

Revista de Direito Brasileira | Florianópolis, SC | v. 26 | n. 10 | p. 144-160 | Mai./Ago. 2020 
nação por sufrágio universal os seus poderes, o que de uma parte aumenta-lhe o prestígio e, de outra banda, lhe afiança posição de inteira independência política perante a esfera do poder legislativo (BONAVIDES, 2001, p.297).

Devido à tamanha importância do cargo do Presidente da República a própria Constituição Federal prevê em seu artigo 85 a existência de crimes de responsabilidade por atos do Presidente em rol taxativo 5 . Da mesma forma, porém para resguardar possíveis persecuções criminais de natureza política que possam atingir a Presidência, existe previsão de regra protetiva em seu art. 86, parágrafo $4^{\circ}$, a qual estabelece que não poderá ser o presidente responsabilizado por atos estranhos ao exercício de suas funções ${ }^{6}$.

Segundo o art. 14 da Lei 1.079/19507 , recepcionado pelo Constituição Federal de 1988, "é permitido a qualquer cidadão denunciar o Presidente da República ou Ministro de Estado, por crime de responsabilidade, perante a Câmara dos Deputados". Tendo o art. 34 dessa lei fixado como sanção a esses crimes a destituição do cargo ou impeachment. Logo, se está diante de possibilidade legal e taxativa da responsabilização penal do Presidente da República. Para tanto, a constituição, prevê no art. 86, a forma e o modo de como se dará o processo e julgamento dos crimes que culminam no impeachment presidencial.

Especialmente na atual conjuntura política do Brasil, desde 2014 instaurou-se uma forte crise política, isso é, um caminho que levou a uma polarização política em virtude de uma eleição disputada voto a voto, onde a candidata Dilma Roussef foi reeleita em 2014 por uma mínima diferença de votos. Essa pequena vantagem que a levou a vitória desencadeou uma crise política sem precedentes, a qual resultou em seu processo de afastamento em 2016 e, nas eleições de 2018, a assunção ao poder do então candidato, com discurso de extrema direita Jair Bolsonaro, tendo como palanque eleitoral um forte combate às políticas aplicadas pela sua antecessora e seu partido.

Longe de perquirir sobre o mérito do impeachment que passou o Brasil em 2016 não há que se negar que um processo como este é traumático para qualquer nação e representa uma "ruptura democrática", pois acaba se eliminando milhões de votos que foram destinados ao candidato eleito. Essas questões sobre os percalços do presidencialismo também foram abordadas por Sartori (1996, p.101) o qual refere que o presidencialismo não tem funcionado bem de um modo geral, com exceção dos Estados Unidos, todos os demais sistemas têm apresentado fragilidade, sucumbindo geralmente a golpes e quebra de continuidade. Assim, as observações traçadas por Sartori se amoldam ao caso brasileiro, onde há sérias dúvidas quanto à legitimidade do desencadeamento do impeachment de 2016, denominado por alguns autores como "golpe de 2016 '.

Nas palavras de Miguel (2016, p.1), um dos expoentes a cunhar o termo "golpe de 2016"

\footnotetext{
${ }^{5}$ Art. 85. São crimes de responsabilidade os atos do Presidente da República que atentem contra a Constituição Federal e, especialmente, contra:

I - a existência da União;

II - o livre exercício do Poder Legislativo, do Poder Judiciário, do Ministério Público e dos Poderes constitucionais das unidades da Federação;

III - o exer cício dos direitos políticos, individuais e sociais;

IV - a segurança interna do País;

V - a probidade na administração;

VI - a lei orçamentária;

VII - o cumprimento das leis e das decisões judiciais.

Parágrafo único. Esses crimes serão definidos em lei especial, que estabelecerá as normas de processo e julgamento.

${ }^{6}$ Art. 86. Admitida a acusação contra o Presidente da República, por dois terços da Câmara dos Deputados, será ele submetido a julgamento perante o Supremo Tribunal Federal, nas infrações penais comuns, ou perante o Senado Federal, nos crimes de responsabilidade. [...] $\S 4^{\circ}$ O Presidente da República, na vigência de seu mandato, não pode ser responsabilizado por atos estranhos ao exercício de suas funções.
}

${ }^{7}$ BRASIL. Lei complementar $\mathrm{n}^{\circ} 1079$ de 10 de abril de 1950. Lei dos Crimes de Responsabilidade e do Processo de Impeachment. Disponível em <http://www.planalto.gov.br/ccivil_03/leis/L1079.htm> acesso em 24 de fev.de 2017.

Revista de Direito Brasileira | Florianópolis, SC | v. 26 | n. 10 | p. 144-160 | Mai./Ago. 2020 
os acontecimentos políticos no ano do impeachment da Presidente Dilma Roussef no Brasil encerraram a experiência democrática iniciada no Brasil desde 1985, especialmente por envolver um novo tipo de golpe no qual não houve a participação das forças armadas. Refere o autor que os acontecimentos de 2016 se basearam para além das instituições políticas clássicas, sendo relevante a oportunidade que os políticos de oposição tiveram ao embarcar na onda dos manifestos políticos que tomaram as ruas em junho de 2013, especialmente tomando uma roupagem de discurso moralista e anticorrupção, o qual estava por trás o interesse em tomar o poder pelos bastidores, marcado fortemente pela insatisfação de alguns setores do PSDB desacreditados na alternância de poder pelo voto, pela vingança do à época Presidente da Câmara dos Deputados Eduardo Cunha e a atuação pelas sombras do Vice-Presidente da República Michel Temer para assumir o comando da nação.

Este padrão de rupturas democráticas foi observado por Moisés (1989, p.47) o qual destaca que o primeiro dilema dos países que estão em processo de transição política, tratando-se primordialmente de tarefas de engenharia institucional, a estratégia de construção da democracia não é uma decorrência natural do fim do autoritarismo. Segundo o autor, as sociedades que saíram de recentes ditaduras (como o Brasil) tendem a enfrentar dificuldades em se transformar em democracias modernas, especialmente pelo peso que a experiência democrática exerce sobre essas sociedades e pelas dificuldades que as forças políticas relevantes estejam comprometidas com o projeto democrático, pelos óbices de conseguirem exercer efetivamente suas tarefas estratégicas.

Entende Moisés (1989, p.47) que qualquer que venha a ser o sentido de superação a crise dos regimes autoritário, impulsionada pelos processos de transição, exige-se a gestação de novas formas de se conceber e de se praticar a política. Segundo o autor fala-se hoje de uma crise no Cone Sul, de uma crise dos partidos políticos, do parlamento e do Estado, enfim, das condições existentes para haver governabilidade o que pressupõe uma profunda revisão do sistema democrático de governo. Ainda, destaca Moisés (1989, p.48) que esse processo incide diretamente sobre a capacidade das forças políticas comprometidas têm de demonstrar soluções capazes de enfrentar os velhos e os novos desafios colocados para essas sociedades.

Gargarella (2010, p.49) também refere que esse padrão se repete na organização política na América Latina baseado em um peculiar pacto liberal-conservador, por meio do qual se estabeleceu o presidencialismo, proveniente dos liberais, os quais defendiam um sistema de freios e contrapesos aos moldes do norte-americano, ao mesmo tempo em que se estabeleceu uma grande concentração de atribuições no Presidente da República, provenientes dos conservadores, com forte viés monarquista.

No mais, Gargarella (2010, p.271) registra a instabilidade política presente na região durante o século XX, a qual entende o autor é um dos efeitos da forte concentração de poderes na figura do presidente, o que ele denomina como "hiperpresidencialismo". Para o autor Nino hiperpresidencialismo é concentração excessiva de poder em apenas uma pessoa:

Resultava claro que o hiperpresidencialismo implicava em concentrar demasiado poder, demasiadas responsabilidades e demasiadas expectativas em uma só pessoa por um período determinado. Qualquer súbita desilusão com o presidente, qualquer queda da sua popularidade ou problema de sua saúde tendia a traduzirse como uma crise do sistema político. Qualquer crise política e econômica se transformava em uma crise sistêmica. ainda pior, dado que o sistema carecia de válvulas de escape para remediar os desajustes, a eleição de um presidente tendia a aparecer como a única saída para sair da crise. (NINO, 1992, p.272)

E ao que parece às previsões de Nino (1992, p.272) foram acertadas, especialmente diante do cenário atual depois do impeachment que perpassa o Brasil após o "mal estar" provocado desde as eleições de 2014 e resultou em um processo de impeachment da Presidente eleita. Para Avritzer (2016, p.7) existe hoje no Brasil uma situação de incômodo com relação à democracia, 
especialmente a partir das manifestações de junho de 2013 e continua até o momento atual, o que pode ser aferido com a ida às ruas de milhões de pessoas para protestar contra os políticos e os atuais índices de insatisfação da população com a classe política ${ }^{8}$.

Especialmente com relação a situação da fragilidade da democracia brasileira é confirmada pelo Índice de Desenvolvimento Democrático de América Latina, o qual classificou o Brasil no ano de 2016 como um desenvolvimento mínimo de democracia na posição $14^{\mathrm{a}}$ na América Latina, ficando inclusive atrás de países como Paraguai, Argentina e México. Segundo o IDD - Lat 2016 um dos desafios da sociedade latino-americana é conseguir um grau de desenvolvimento democrático que afaste as tendências negativas que vigoram até o presente, produto de autoritarismo, corrupção, marginalização de segmentos da população, fortes desigualdades e ineficiência das instituições políticas. Diante dessa situação na América latina gera-se um quadro que não é propício a gerar políticas de longo prazo e tampouco uma estabilidade político-democrática (IDD Lat, 2016, p.1)

E nesse ponto se faz necessário rememorar sobre a importação do Presidencialismo norte americano para o Brasil como sendo o modelo mais adequado para a realidade da América latina, o que acabou não se concretizando e resultando em menos de 20 anos em 2 processos de impedimento (Fernando Collor de Mello 1991 - 1992 e Dilma Roussef 2011 - 2016). O constitucionalismo brasileiro sofreu forte influência na escolha do sistema presidencialista pelos Estados Unidos, formando aqui também governos de coalizão. Ocorre que o processo de formação do Brasil é significativamente diferente do processo de formação norte americano, a começar pela constituição, pois a deles data de 1787 e vige até hoje, ao passo que a brasileira surgiu pela primeira vez em 1824 e não nasceu como um processo de luta pela liberdade, mas sim foi outorgada ainda no período do império (ANJOS, 2015, p.51).

Assim, como demonstrado, os dois países tiveram bases de formação do constitucionalismo muito diferentes, pois enquanto nos Estados Unidos se discutia sobre a liberdade de religião, no Brasil vivia-se um império que adotava uma religião oficial. Dessa forma, ao se importar o sistema posto nos Estados Unidos para o Brasil, necessariamente, precisou-se fazer uma série de adaptações chegando ao ponto de termos um funcionamento institucional bastante peculiar, o chamado presidencialismo de coalizão.

A Constituição brasileira optou por manter o sistema presidencialista, apesar do art. $2^{\circ}$ do Ato das Disposições Constitucionais Transitórias prever um plebiscito a ser realizado para consultar a população quanto a alteração deste sistema. Segundo Bonavides (2010, p.222) relata que os primeiros republicanos no Brasil eram parlamentaristas e não lhes passava pela cabeça a consagração do sistema presidencial, sendo que os autores do célebre Manifesto Republicano de 1870 não tinham identificação com esse sistema.

Ainda, Bonavides faz uma severa crítica ao modelo presidencialista brasileiro ao elencar que:

Quando ao Presidencialismo, é modelo malogrado que ao longo de cem anos de república demonstrou ser a mais nociva e inidônea das formas usuais de governo, pelo menos no atual grau de desenvolvimento da sociedade brasileira. Outra coisa ele não fez aqui senão gerar no ventre de suas crises a ditadura, a sedição militar, o tumulto social, a rigidez oligárquica e uma sensível atrofia do sentimento de responsabilidade pública nos titulares do poder. (BONAVIDES, 2010, p. 220).

Em resumo, o presidencialismo brasileiro acabou efetivando-se de uma maneira bastante atípica do modelo de repartição de poderes norte americano, o qual serviu de inspiração para o

\footnotetext{
${ }^{8}$ Sobre o tema Figueiredo (2014, p.23) descreve que junho decorre de uma espiral de silêncio que até aquele momento encontravam-se sem voz. Segundo o autor todos aqueles que não acreditavam no Brasil das versões otimistas, a partir daquele momento, passaram a ter voz e espaço. Ainda, todas as posições contrárias aos otimistas ganharam capacidade de expressão, gerando uma quebra de hegemonia e se abrindo o caminho para novos alinhamentos políticos e sociais.
}

Revista de Direito Brasileira | Florianópolis, SC | v. 26 | n. 10 | p. 144-160 | Mai./Ago. 2020 
Brasil. Diferentemente do que ocorre aqui, o modelo norte-americano é caracterizado especialmente pela divisão e separação dos poderes entre o Presidente e o Congresso Nacional. Lá a concepção de separação dos poderes consiste essencialmente em "afastar" o executivo do apoio parlamentar, enquanto a partilha de poder significa que o executivo se baseia no apoio parlamentar, que lhe é necessário. Com esse critério, pode-se afirmar que nos Estados Unidos há efetivamente uma divisão de poderes (SARTORI, 1996, p.101).

E ao continuar a análise sobre o sistema de divisão de poderes norte-americano Sartori relata que embora o sistema presidencialista americano leve a um governo forte e eficaz, não desmente a afirmativa que uma estrutura de poder dividida conduz mais facilmente à paralisia ou impasses. Então, questiona o autor como o sistema americano ainda funciona e chega à conclusão que a divisão de poder lá tem sido compensada não apenas com maiorias sintonizadas presidencialistas no Poder Legislativo, mas também, na prática, por atuações consorciais, em especial a convergência bipartidária no campo da política externa.

E nesse ponto há de se pontuar sobre o presidencialismo de coalizão brasileiro, o qual se distingue fortemente do sistema americano primordialmente pela realidade eleitoral partidária no Brasil, uma vez que atualmente há em funcionamento com registro perante o Tribunal Superior Eleitoral 35 (trinta e cinco) partidos políticos, das mais diversas siglas, tamanhos e bases ideológicas. Ainda, há outros 63 (sessenta e três) partidos em processo de formação perante a corte eleitoral. Nesse diapasão se questiona, há como o sistema de freios e contrapesos funcionar no Brasil tendo o Presidente da República que formar bases de coalisão com 35 partidos políticos?

O excesso de partidos políticos no Brasil é um reflexo do sistema eleitoral proporcional para eleições do Poder Legislativo, o qual tende a reduzir a quase nada o fenômeno da subrepresentação, pois o número de votos válidos é dividido pelas cadeiras a serem ocupadas na câmara, obtendo-se o quociente eleitoral, o qual é a proporção que cada partido conseguirá eleger de seus representantes (FERREIRA FILHO, 2001, p.174). Entretanto, é necessário debater até qual ponto o sistema eleitoral proporcional no Brasil favorece a multiplicação de partidos políticos, possibilitando a criação de partidos sem qualquer importância e cuja única finalidade é tirar proveito de algum possível poder de barganha em votações e eleições importantes (SILVA, 1999, p.165). Relata o autor que é preciso esclarecer que a existência dos partidos políticos isoladamente não pode ser tomada como um problema, pois a sociedade é heterogênea e a representação de diversos setores sociais no Congresso Nacional é o espelhamento dessa sociedade.

O apoio partidário no Poder Legislativo é um dos pilares fundamentais para se repensar o a teoria da separação dos poderes, especialmente sob o viés do sistema de freios e contrapesos, uma vez que um Congresso Nacional forte compartilhando poder com o Presidente da República garante uma maior estabilidade democrática ao país. Ao comentar sobre os percalços da democracia brasileira Sartori (1996, p.149) comenta sobre a eleição do "forasteiro" Presidente Fernando Collor (1990-1992) o qual improvisou um partido ao fazer sua campanha e se elegeu com um partido que conseguiu menos de $10 \%$ de cadeiras no Congresso Nacional, obviamente não conseguindo terminar seu mandato sem apoio parlamentar.

Assim, têm-se no Brasil um padrão de democracia fortemente pessoalizado, no qual a figura do Presidente da República é tão forte que mediante qualquer crise institucional no Poder Executivo acaba por comprometer todo o funcionamento do Estado Brasileiro. Dessa forma, necessário se faz pensar mecanismos de controle de responsabilidade política ágeis que garantam uma maior estabilidade e fluidez para saída de crises, eis que o presidencialismo nos moldes adotados enfrenta sérias dificuldades para atender a realidade institucional brasileira.

\section{A NECESSIDADE DE APRIMORAMENTO DA DEMOCRACIA PARTICIPATIVA NO BRASIL: A PROPOSTA DE RECALL DO PRESIDENTE DA REPÚBLICA NA PEC 21/2015}


Segundo Bonavides (2000, p.27) do ponto de vista teórico faz-se mister acrescentar e admitir que a democracia participativa transcende a noção obscura, abstrata e irreal do povo nos sistemas representativos e transcende, por igual, os horizontes jurídicos da teoria clássica da separação dos poderes. No entanto, o faz sem dissolvê-la, pois em rigor a vincula numa fórmula mais clara, positiva e consistente ao povo real, o qual tem a investidura da soberania sem disfarce. Nas palavras do autor a democracia é um direito constitucional progressivo e vanguardeiro, o qual veio para repolitizar a legitimidade e reconduzi-la às suas nascentes históricas, ou seja, ao período no qual foi a bandeira de liberdade dos povos (BONAVIDES, 2000, p.33).

Nas palavras de Arendt (1994, p.14) o poder precisa de apoio e da organização popular para se manter, sendo do consentimento da opinião pública que se sustenta a legitimidade de um governo democrático. Destaca a autora que a democracia participativa pressupõe a co-participação de cidadãos livres, uma vez que eles deixam de ser governados por uma elite que deriva seus poderes dos conselhos de assessorias intelectuais, para então formar um espaço de participação na própria esfera pública, compreendida como o espaço do bem comum, o qual interessa a todos os indivíduos ainda que sob perspectivas diferentes (Arendt, 1999, p.67).

Ensina Avritzer (2016, p.71) que o ponto de partida da atual crise política e polarização ideológica no Brasil se deu justamente a partir das manifestações de junho de 2013 com o rompimento dessa política de participação social no Brasil, especialmente entre os anos de 2011 e 2013. Destaca o autor que essa ruptura foi paulatina e se deu à medida que se acumularam conflitos de movimentos sociais, tais como o ambientalista e o indígena com o governo federal. Ainda, para acentuar esse processo de ruptura e indignação nas ruas o país aprovou uma série de legislações para acelerar o processo de obras para receber a copa do mundo, o que gerou muitas críticas e mobilizações de organizações que lutam por reforma urbana, acontecimentos que restaram por estremecer a boa relação de participação política dessas organizações com o governo federal.

Ao definir a democracia participativa Bonavides (2001, p. 275) refere que se trata de modalidade em que se alteram as formas clássicas de democracia representativa para aproximá-la cada vez mais de uma democracia direta. Destaca o autor que com a democracia semi-direta a alienação política da vontade popular se faz apenas parcialmente, pois a soberania está com o povo e o governo a exerce, sendo que as matérias mais importantes da vida pública pertencem ao povo. Logo, determinadas instituições como o referendo, a iniciativa, o veto e o direito de revogação faz a efetiva intervenção do povo, garantindo-lhe um poder de decisão de última instância, supremo, definitivo e incontrastável (BONAVIDES, 2001, p.275).

No mesmo sentido Streck e De Moraes (2014, p.124) destacam que as fórmulas da chamada democracia participativa constituem alternativas possíveis para a rearticulação de espaços públicos que constituam de tamanha legitimidade que transponham até mesmo os canais de democracia representativa, escapando inclusive as insuficiências no que tange a formação de opinião em sociedades cujos sistemas de informações são controlados por minorias (Streck e De Moraes, 2014, p.123). Tal possibilidade é um forte argumento para defendê-la, especialmente sob o argumento que oito famílias controlam os grupos de televisão no Brasil, além de também atuarem em mídia impressa e eletrônica, além de três outros grupos familiares que controlam as ramificações da mídia brasileira: grupo Abril, O Estado de S. Paulo e o grupo Folha de S. Paulo). Assim, $90 \%$ da mídia brasileira é controlada por apenas quinze grupos familiares (LIMA, 2001, p.106).

Para Santos e Avritzer (2002, p. 65) o Brasil e a Índia são os países nos quais as potencialidades da democracia participativa mais se manifestam, pois a Assembleia Constituinte aumentou a influência de diversos atores sociais nas instituições políticas do país por novos arranjos participativos, ou seja, o texto constitucional foi capaz de incorporar novos elementos culturais surgidos na sociedade, na institucionalidade emergente, abrindo assim espaço para a democracia participativa. Ainda, defendem os autores a tese que não existe nenhum motivo para a democracia assumir uma só forma, pelo contrário, o multiculturalismo e as experiências recentes 
de participação apontam no sentido da deliberação pública e o adensamento da participação - a chama demodiversidade.

A Constituição da República Federativa do Brasil assegurou que "todo poder emana do povo, que o exerce por meio de seus representantes eleitos ou diretamente, nos termos desta Constituição" (Art. 1 1 , Parágrafo único, CRFB/88), sendo que o Brasil adotada a democracia participativa no seu texto constitucional, ou seja, a coexistência da democracia representativa com os institutos de democracia direta tais como plebiscito, referendo e a iniciativa popular ${ }^{9}$. Buscando ampliar os institutos de democracia participativa no Brasil insurge-se a Proposta de Emenda à Constituição 21/2015 do Senado Federal, a qual busca incluir no rol do Art. 14 da CRFB/88 os institutos jurídicos do veto popular e do recall.

$\mathrm{O}$ instituto do recall ainda pouco conhecido no Brasil é utilizado em alguns estados federados nos Estados Unidos da América, sendo que foi amplamente divulgado pela mídia a sua utilização no estado da Califórnia em 2003, quando o governador do Partido Democrata, Devis Gray, teve o seu mandato revogado e foi substituído por meio de recall pelo candidato do Partido Republicano, o astro de cinema Arnold Schwarzenegger ( BBC Brasil, 2003). O que mais chamou a atenção nesse processo foi o próprio procedimento de destituição do representante eleito do povo e as novas eleições, como um aprimoramento da democracia, uma vez que este instituto se consolida como uma espécie de arrependimento eleitoral, permitindo a revogação do mandato de governantes que frustraram seus eleitores por incompetência ou por traição.

Refere Dallari (2011, p.155) que o recall é um instituto jurídico típico dos Estados Unidos que se aplica a revogar a eleição de um legislador ou funcionário eletivo, ou para se reformar decisão judicial que trata de constitucionalidade de lei, sendo que, no primeiro caso, o qual se exige que determinado número de eleitores requeira uma consulta ao eleitorado sobre a manutenção do mandato, é necessário que os requerentes prestem uma caução em dinheiro. Na hipótese da maioria decidir pela revogação, o eleito perde o cargo e, caso o recall não seja aprovado o mandato continua e o Estado fica com o dinheiro depositado.

Ensina Caggiano (1987, p. 30) que o recall é o instituto jurídico no qual confere ao eleitorado a faculdade de, antes do término previsto para o fim do mandato conferido a um candidato eleito, por meio de uma nova manifestação do povo, destituí-lo, indicando já naquele ato um sucessor. Nas palavras de Ávila (2009, p.55) com relação ao procedimento o recall nos Estados Unidos é dividido em duas fases distintas, sendo que na primeira se assemelha muito ao procedimento de iniciativa popular, uma vez que para dar início ao procedimento é necessário parcela do eleitorado que confirme a sua intenção de instaurá-lo para, após, iniciar a segunda fase, na qual os eleitores decidem por meio de votação sobre a destituição e substituição do agente público.

Segundo Beçak ( 2017, p.365) a questão do procedimento do recall é multifacetada, mas embora as normatizações estrangeiras tenham as suas peculiaridades em cada Estado, pode se traçar alguns pontos em comum como: a) iniciativa popular; b) recebimento na casa legislativa; c) verificação dos requisitos que houver; d) convocação da consulta popular; e) consulta popular programada. Na hipótese de a consulta ser aprovada há possibilidade de nomeação de um suplente até a escolha de novo candidato ou concomitantemente à consulta já escolher possível substituto. Ainda, se rejeitada a consulta também há previsão de prazo para limitação de nova consulta.

E nesse ponto cabe destacar que Bonavides (2001, p.379) faz a diferenciação entre recall e Abbeufungrecht, sendo que entende o autor que o primeiro é a revogação individual, o qual qualifica o eleitorado a destituir funcionários cujo comportamento, por qualquer motivo, não lhe

\footnotetext{
${ }^{9}$ Art. 14, CRFB/88. A soberania popular será exercida pelo sufrágio universal e pelo voto direto e secreto, com valor igual para todos, e, nos termos da lei, mediante:

I - plebiscito;

II - referendo;

III - iniciativa popular.
}

Revista de Direito Brasileira | Florianópolis, SC | v. 26 | n. 10 | p. 144-160 | Mai./Ago. 2020 
esteja agradando. Determinado número de cidadãos, geralmente a décima parte do corpo de eleitores, apresenta petição assinada com as acusações contra aquele que perdeu a confiança popular, pedindo sua substituição no cargo que ocupa ou intimidando para que se demita do exercício de seu mandato. Já o Abbeufungrecht é a forma de revogação coletiva, aqui não se trata de recall, do cassar o mandato de um indivíduo, mas o de toda uma assembleia, sendo que o procedimento será o mesmo (com requerimento de uma parcela do eleitorado) e aquela assembleia só terá o fim do seu mandato após o final da votação do Abbeufungrecht, mecanismo este adotado em sete cantões da Suíça.

Conforme lembra Caliman (2016, p.304) nenhuma Constituição Federal no Brasil trouxe até hoje a previsão do recall em seu texto ou mesmo do juízo político, mas já houve no país a previsão de recall em constituições estaduais como nos Estados de Goiás (1891), São Paulo (1891), Rio Grande do Sul (1891) e Santa Catarina. Leciona o autor que embora se tenha notícia de tais previsões em nível estadual até hoje não há notícia da efetivação do recall, apontando-se como fator de não operacionalização a dificuldade no recolhimento de assinaturas para início do processo, somado ao coronelismo impregnado na área política.

No mesmo sentido Lorencini e Gundim (2017, p.376) destaca que a utilização de revocatória de mandato nos países latino-americanos não seja algo comum ela apresenta algumas diversidades das quais é possível extrair algumas premissas que indicam a adoção ou não do recall. Ensina o autor que a normatização do recall nos países da América-latina apresenta alguns traços em comum, a saber: a) a normatização da revocatória do mandato em quase todos os países traz um rol taxativo e bem delimitado, prazos, requisitos formais de quórum de admissibilidade e de destituição; b) a respeito de se verificar um grau de agitação política no país em função do recall este ainda aparenta ser menos traumático que o processo de impeachment ${ }^{10} \mathrm{e} ; \mathrm{c}$ ) a revocatória do mandato se apresenta como instrumento de democracia participativa e alerta aos representantes que o povo é sempre o titular do poder, de modo que não representando os interesses destes os governantes podem ser substituídos.

Destaca Ávila (2009, p.102) que muitos países na América Latina possuem a previsão nas suas próprias constituições do Recall de seus governantes, a exemplo da Venezuela que prevê em seu Art. 72 o instituto com o nome referendo revocatório, sendo que conforme o dispositivo todos os cargos que decorrem de eleições populares podem ser objeto de revogação. Ainda, a Constituição do Peru em seu Art. 31 prevê que todos os cidadãos têm direito a participar dos assuntos políticos com pedidos de referendo, iniciativa legislativa ou remoção. A Constituição da Colômbia prevê que os cidadãos têm o direito de iniciativa e controle do poder legislativo por meio dos plebiscitos, referendos, consultas e, sendo ainda permitido, revogar o mandato dos eleitos de acordo com a própria constituição e respectiva lei complementar. Por fim, o autor destaca que embora a Argentina não possua tal previsão em nível nacional o instituto lá é previsto na lei estadual, a exemplo da Constituição de Córdoba em seu Art. 183, item 4.

E neste ponto são importantes os ensinamentos de Bonavides (2001, p.297) que os poderes do Presidente da República derivam da própria nação por sufrágio universal, o que de uma parte aumenta o seu prestígio e de outra banda lhe afiança inteira independência política perante a esfera do poder legislativo. No entanto se questiona: e como proceder quando o Presidente da República perde a confiança do povo que o elegeu? Foi basicamente o que ocorreu em 2016 com o processo de impeachtment da mandatária Dilma Roussef, a qual conseguiu atingir o índice de $65 \%$ de

\footnotetext{
10 Ainda cabe registrar que no recall não se discute “crime de responsabilidade" pelo agente destituído, o que certamente gera um menor grau de instabildade tanto para a população quanto para o representante. Ainda, no recall mesmo após iniciado o processo não há figura de afastamento provisório do chefe do executivo, como ocorre no caso do impeachment, agravando ainda mais a instabilidade política e, por fim, a legitimidade para iniciar e concluir o processo de recall é do povo, o qual se utiliza de instrumento de democracia direta para tomar a decisão, diferentemente do impeachment em qua a participação direta inexiste e o processo é iniciado, na maioria das vezes, por interesses da oposição. (LORENCINI; GUNDIM, 2017, p.376)
} 
rejeição ao seu mandato no ano de 2015 (Instituto DataFolha), sofrendo um processo de impedimento pelo Congresso Nacional em 2016.

Por isso o maior debate que se deu com o processo de impeachment da Presidente Dilma Rousseff em 2016 foi justamente sobre a (in)existência de crime de responsabilidade previsto no rol do Art. 85, VI, da Constituição Federal, o qual trás a previsão dos crimes de responsabilidade do Presidente da República ${ }^{11}$. Segundo Dalmo Dallari em entrevista a Puff $(2015$, p.1) não restou qualquer comprovação de um envolvimento da Presidente em atos de corrupção, sendo que podem ter havido até irregularidades formais, administrativas, mas não configuram crime de responsabilidade. Assim, a própria Presidente deposta Dilma Rousseff alegou na data do seu afastamento da presidência o andamento de um golpe parlamentar no Brasil para retirá-la do poder.

Nas palavras de Comparato o cenário do impeachment de Dilma Rousseff em 2016 é totalmente diferente daquele que sofreu o Presidente Collor em 1992, pois no caso de Dilma não havia nenhum respaldo legal para tanto, sendo que o Congresso Nacional retirou um mandato que foi dado pelo povo, bem como os fatos que embasaram o pedido de afastamento deveria se tratar ao período daquele mandato, sendo que as ditas pedaladas fiscais se deram do mandato anterior. No entanto, o que se presenciou foi uma manobra parlamentar para se retirar o mandato da Presidente Dilma Rousseff por ausência de apoio da base aliada no Congresso Nacional (PUFF, 2015, p.1).

Por consequência esse movimento de afastamento da Presidente da República do Brasil em 2016 representou uma quebra das regras básicas da adoção do sistema presidencialista, pois nesse sistema de governo os poderes do chefe da nação derivam do povo que o elegeu, e não do Congresso Nacional como no parlamentarismo. Ainda, a responsabilidade do Presidente da República é penal e não política, uma vez que responde ele por crime de responsabilidade no exercício da competência constitucional (BONAVIDES, 2000, p.297). Assim, pode-se questionar: e qual o instituto jurídico no Brasil para a saída de crises no Poder Executivo por irresponsabilidade política? Qual a saída de um Presidente da República encurralado politicamente por um Congresso Nacional?

Nos ensina novamente Lorencini e Gundim (2017, p.376) que não seria inviável, no plano teórico, a convocação do recall pela vontade unilateral de uma única autoridade, como no caso do parlamentarismo, quando ocorre a cisão entre o Chefe de Estado e o Chefe de Governo. Asseveram os autores que há possibilidade teórica que a própria autoridade decida sobre a continuidade ou não no cargo, sendo que os autores explicam que em sistemas presidencialistas, em momentos de crise, poderia o Chefe do Poder Executivo convocar o seu próprio recall como legitimador de seu mandato, da mesma forma que convoca plebiscito para referendar decisões políticas.

Essa possibilidade embora desafiadora se apresenta como uma solução política plausível para um país presidencialista como o Brasil, o qual apresenta uma democracia fortemente delegativa $^{12}$ como os demais países da América-Latina. Durante o processo de impeachmant de

\footnotetext{
${ }^{11}$ Art. 85. São crimes de responsabilidade os atos do Presidente da República que atentem contra a Constituição Federal e, especialmente, contra:

I - a existência da União;

II - o livre exercício do Poder Legislativo, do Poder Judiciário, do Ministério Público e dos Poderes constitucionais das unidades da Federação;

III - o exercício dos direitos políticos, individuais e sociais;

IV - a segurança interna do País;

V - a probidade na administração;

VI - a lei orçamentária; (grifo nosso).

VII - o cumprimento das leis e das decisões judiciais.

Parágrafo único. Esses crimes serão definidos em lei especial, que estabelecerá as normas de processo e julgamento.

12 Segundo O’ Donnell (1991, p.25) o Brasil (como demais países da América Latina) vivencia hoje um de modelo de democracia delegativa a qual se funda na premissa que quem ganha a eleição presidencial é autorizado a governador o país como lhe convém e, na medida em que as relações de poder permitam, até o final de seu mandato. Leciona o
} Revista de Direito Brasileira | Florianópolis, SC | v. 26 | n. 10 | p. 144-160 | Mai./Ago. 2020 
Dilma Rousseff a presidente afastada declarou até o seu último dia no mandato que estava sendo vítima de um golpe parlamentar no país. No entanto, qual o mecanismo disponível para Dilma Rousseff legitimar seus 54 milhões de votos perante um Congresso Nacional prestes a cassá-la? Nessa situação, embora bastante arriscado, um pedido de recall poderia criar-lhe ânimo e força política para concluir o seu mandato com o apoio do povo, uma vez que não o conseguiu perante o Poder Legislativo.

Nesse sentido a Proposta de Emenda à Constituição 21/2015 após tramitar pelas comissões do Senado Federal e ter um projeto substitutivo aprovado, apto a deliberação em plenário, restou pactuado na proposta a inclusão dos seguintes artigos na CRFB/88:

Art. 86-A. O mandato do Presidente da República poderá ser revogado, mediante proposta subscrita por eleitores em número não inferior a um décimo dos que compareceram à última eleição presidencial, distribuídos por pelo menos quatorze Estados, cada um deles com não menos de cinco por cento dos eleitores que votaram no referido pleito.

$\S 1^{\circ}$ A proposta de revogação será apreciada pela Câmara dos Deputados e pelo Senado Federal, sucessiva e separadamente, e considerada aprovada se obtiver o voto favorável da maioria absoluta dos membros de cada uma das Casas. (grifo nosso).

$\S 2^{\circ}$ Aprovada a proposta de revogação, será convocado referendo, na forma do inciso XV do art. 49, para ratificá-la ou rejeitá-la.

$\S 3^{\circ}$ Revogado o mandato, será declarado vago o cargo de Presidente da República, aplicando-se o disposto no art. 79. (grifo nosso)

$\S 4^{\circ}$ É vedada proposta de revogação durante o primeiro e o último ano do mandato.

$\S 5^{\circ}$ É vedada a apreciação de mais de uma proposta de revogação por mandato.

Além de tal previsão de inclusão do Art. 86-A na CRFB/88 a Emenda 2/CCJ (substitutivo), de autoria do Senador Antonio Anastasia, também inclui o $\S 3^{\circ}$ no Art. 28, concedendo a possibilidade de extensão do recall para os chefes do Poder Executivo Estadual e Municipal, bem como a data de vigência a partir de janeiro de $2019^{13}$. O substitutivo ao projeto original da PEC 21/2015 teve um avanço comparado com aquele proposto originalmente, saindo de um panorama minimalista, porém com o desafio de regulamentar a matéria no próprio texto constitucional formando um recall a brasileira ${ }^{14}$.

O instituto do recall na PEC 21/2015 avançou no sentido que estabeleceu um quórum mínimo de deliberação fixado em 1 décimo daqueles que compareceram nas últimas eleições, patamar esse coerente com o percentual fixado nos E.U.A. e em conformidade com as lições do doutrinador Paulo Bonavides. Ainda, fixou a distribuição do quórum de instauração em pelo menos quatorze estados, sendo pelo menos cinco por cento dos eleitores naquela unidade federativa, respeitando a diversidade e o federalismo do Estado brasileiro.

No entanto, tal substitutivo criou um juízo de admissibilidade sui generis, o qual se refere por ora como recall à brasileira por ausência de termo próprio. Nos moldes do $§ 1^{\circ}$ da PEC 21/2015

autor que o presidente é a encarnação da nação, o principal fiador do "interesse maior da nação", afinal, ele foi autorizado a governar como achar conveniente.

${ }^{13}$ Art. $2^{\circ} \mathrm{O}$ art. 28 da Constituição Federal passa a vigorar acrescida do seguinte $\S 3^{\circ}$ :

$\S 3^{\circ}$ Os Estados e o Distrito Federal disporão, nas respectivas Constituições e Lei Orgânica, sobre a revogação de mandato do Governador."

Art. $3^{\circ}$ Esta Emenda Constitucional entra em vigor em $1^{\circ}$ de janeiro de 2019.

${ }^{14}$ Expressão ora cunhada para definir a descaracterização do instituto do recall no substitutivo da PEC 21/2015, inspirada no livro Impeachment à Brasileira: Instrumento de Controle Parlamentar? de Antonio Riccitelli.

Revista de Direito Brasileira | Florianópolis, SC | v. 26 | n. 10 | p. 144-160 | Mai./Ago. 2020 
há previsão de juízo de admissibilidade pela Câmara dos Deputados e pelo Senado Federal, sucessiva e separadamente, com aprovação favorável pela maioria absoluta dos membros de cada casa (grifo nosso). Esse juízo de admissibilidade descaracteriza toda a essência do recall, pois o objetivo de tal instituto é justamente dar ao povo o poder de decidir pela manutenção de seus eleitos ou não, ou seja, o requisito de admissibilidade é o próprio número de assinaturas em entes federados exigidos. Em suma, para a aprovação de um recall do mandatário do Poder Executivo o juízo de admissibilidade seria semelhante ao impeachment, o qual tem uma acepção de atribuição por crime de responsabilidade (exigência de dolo) e não de irresponsabilidade política com a nação.

Ainda, não menos importante o substitutivo apresentado na PEC 21/2015 retirou a previsão de incluir o recall nos incisos do Art.14 da CRFB/88 e moveu para o pretendo Art. 86-A na seção III, a qual trata "Da Responsabilidade do Presidente da República", sendo que os Art. 85 e 86 da CRFB/88 tratam especialmente sobre a taxatividade dos crimes de responsabilidade do Presidente da República, os quais exigem dolo. Em suma, a previsão do recall deveria ser inclusa como originalmente prevista no Art. 14, pois esta modalidade não exige dolo e é um dos instrumentos de democracia participativa como o plebiscito e referendo, já previstos naquele artigo. Em suma, seria coerente que o recall estivesse previsto naquele artigo com regulamentação em lei complementar, como os demais institutos já legislados constitucionalmente.

Por fim, tal PEC prevê que na hipótese de revogação do mandato do Presidente da República quem assume o cargo é o Vice-Presidente da República, outra total distorção do instituto do Recall, o qual não se confunde com a figura do impeachment. No primeiro o povo é chamado a decidir sobre a permanência ou não do mandatário por ele eleito, bem como, na mesma ocasião, já se decide sobre quem será o substituto na hipótese de revogação. Em suma, de nada adiantaria a adoção de um recall no Brasil com a previsão de assunção de um vice ao poder, inclusive podendo vir a fomentar a atuação de Vice-Presidentes da República para derrubada de um mandatário e assunção ao poder por interesses políticos divergentes.

\section{CONSIDERAÇÕES FINAIS}

Ao cabo deste trabalho são necessárias algumas considerações sobre o cenário que se vislumbra para o presidencialismo no Brasil. Com a promulgação da Constituição Federal de 1988 houve uma preocupação em garantir ampla liberdade de organização e formação dos partidos políticos, adotando o pluripartidarismo como um dos fundamentos do Estado Democrático de Direito. Entretanto, esse pluripartidarismo acabou por ocasionar um presidencialismo de coalizão no Brasil, seriamente dificultoso para o Presidente da República eleito formar suas bases de apoio no Congresso Nacional, especialmente diante da quantidade de partidos políticos no Brasil.

Não obstante, vivencia-se no Brasil o fenômeno do hiperpresidencialismo, o qual também é perceptível em outros países da América Latina que vivenciaram ditaduras militares em um passado recente. Esse cenário resulta em um excesso de expectativa na figura do Presidente da República, o qual tem os seus poderes políticos advindos da própria nação, modelo esse de democracia delegativa o qual é fortemente pessoalizado e individualista. Ainda, restou consignado a dificuldade institucional em lidar com as crises do Poder Executivo quando o Presidente da República perde o apoio do Congresso Nacional ou da própria população para se concluir o seu mandato.

Assim, apontou-se que inexiste no Brasil um instituto jurídico-constitucional disponível para a retirada do Presidente da República pela via legal da responsabilidade política com aqueles que o elegeram. Diante desse dilema, resultou em 2016 o processo de Impeachment por irresponsabilidade política e perda de apoio no Congresso Nacional da Presidente Dilma Rousseff.

Ainda, diante da falta de apoio político no Congresso Nacional da mandatária do executivo durante o ano de seu afastamento seria um caso típico de chamamento de recall, pois os próprios eleitores poderiam decidir sobre a continuidade de seu mandato, bem como sobre a adoção de um 
candidato substituto com uma agenda de esquerda, centro ou direita. Ao contrário sensu, resultou na assunção de um Vice-Presidente da República que implementou uma agenda política que não foi chancelada pela nação. Em síntese, é necessário aprimorar os institutos de democracia participativa no Brasil para o próprio fortalecimento do Poder Executivo e legitimidade dos atos do Presidente da República.

Conforme demonstrado a PEC 21/2015 do Senado Federal a qual inicialmente se saiu muito bem com essa proposta de implementação do recall para a realidade institucional brasileira acabou sofrendo sérias alterações nas comissões do Senado Federal, culminando com a aprovação da emenda 2 - CCJ (substitutivo) distorcendo seriamente o instituto do recall importado do direito estadunidense, formando uma verdadeira proposta de "recall a brasileira", termo utilizado por ausência de outro para melhor defini-lo. Condicionar a aprovação de um recall que atingiu os critérios de assinaturas e diversidade de unidades federativas é retirar do povo a própria noção de democracia participativa, uma vez que é ele o detentor do poder o qual pode conceder ou retirar o mandato do Presidente da República.

Por fim, ainda a PEC 21/2015 ao invés de adotar o caminho da experiência norteamericana na qual o povo é chamado a consulta sobre o recall e, votando sim, já escolhe o substituto para o mandatário, optou por ir à direção contrária e prever a assunção do VicePresidente da República, confundindo as previsões do recall com aquelas previstas para o processo de Impeachment. Essa opção não reforça em nada a noção de democracia participativa, eis que é do povo a prerrogativa de escolher o substituto do mandatário o qual está sendo deposto, conforme adoção do instituto recall em outros países, nos moldes apontados nessa pesquisa.

\section{REFERÊNCIAS}

ANJOS, João Guilherme Sampaio dos. A teoria da separação de poderes de Montesquieu e as experiências constitucionais dos EUA e do Brasil. In: VICTOR, Sérgio Antônio Ferreira (Org.). Separação de Poderes. Brasília: Idp, 2015.

ARENDT, Hannah. A condição humana. Rio de Janeiro: Forense Universitária, 1999. .

ARENDT, Hannah. Sobre a violência. Rio de Janeiro: Relume Dumará, 1994.

ÁVILA, Caio Marcio de Brito. Recall - a revogação do mandato político pelos eleitores: uma proposta para o sistema jurídico brasileiro. 2009. Tese (Doutorado em Direito do Estado) Faculdade de Direito, Universidade de São Paulo. São Paulo, 2009.

AVRITZER, Leonardo. Impasses da democracia no Brasil. 1. ed. Rio de Janeiro: Civilização Brasileira, 2016.

BARROS, Sérgio Resende de. Medidas, Provisórias? Disponível em < http://www.srbarros.com.br/pt/medidas---provisorias-.cont> Acesso em 02/10/2017.

BBC Brasil. Tire suas dúvidas sobre o 'recall' na Califórnia. Disponível em < https://www.bbc.com/portuguese/noticias/story/2003/10/031007_californiaduvidasmp.shtml> Acesso em 05/ago/2018.

BEÇAK, Rubens. Reforma política, aprofundamento dos meios de participação democrática e a questão do recall. In: CAGGIANO, Monica Herman Salem (org.). Reforma política: um mito inacabado. Barueri, SP: Manole, 2017.

BONAVIDES, Paulo. Ciência Política. 10ª ed. São Paulo: Malheiros, 2001. 
BONAVIDES, Paulo. Curso de Direito Constitucional. 25. ed. São Paulo: Malheiros, 2010.

BRASIL. Lei complementar no 1079 de 10 de abril de 1950. Lei dos Crimes de Responsabilidade e do Processo de Impeachment. Disponível em

<http://www.planalto.gov.br/ccivil_03/leis/L1079.htm> acesso em 24 de fev.de 2017.

BRASIL. Senado Federal. Disponível em < http://legis.senado.leg.br/sdleg-

getter/documento?dm=5366309\&disposition=inline\#Emenda2> Acesso em 05/ago/2018.

BRASIL. Senado Federal. Disponível em:

http://www12.senado.leg.br/noticias/materias/2016/12/28/impeachment-de-dilma-rousseffmarca-ano-de-2016-no-congresso-e-no-brasil> acesso em 20 de fev. de 2017.

CAGGIANO, Monica Herman Salem. Sistemas eleitorais x representação política. 1987. Tese (Doutorado) - Faculdade de Direito, Universidade de São Paulo, São Paulo, 1987.

CALIMAN, Auro Augusto. O recall no Estado de São Paulo. Revista de Informação Legislativa, Brasília, v.42, n. 165. jan./mar. 2005.

COMPARATO, Fábio Konder. Comparato: “O impeachment hoje é absolutamente ilegítimo". Disponível em < https://apublica.org/2015/12/truco-comparato-o-impeachment-hoje-eabsolutamente-ilegitimo> Acesso em 4/ago/2018.

DALLARI, Dalmo de Abreu. Elementos de teoria geral do Estado. 30. ed. São Paulo: Saraiva, 2011.

FERREIRA FILHO, Manoel Gonçalves. A democracia no limiar do Século XXI. São Paulo:Saraiva, 2001.

FIGUEIREDO, Rubens. A “espiral do silêncio” e a escalada da insatisfação. In: FIGUEIREDO, Rubens (org.). Junho de 2013: a sociedade enfrenta o Estado. São Paulo: Summus, 2014.

GARGARELLA, Roberto. La sala de máquinas de la Constitución. Dos siglos de constitucionalismo en América Latina. Buenos Aires, 2010.

INSTITUTO DATAFOLHA. Avaliação da presidente Dilma Rousseff. Disponível em < http://media.folha.uol.com.br/datafolha/2015/06/22/avaliacao-dilma-intencao-de-voto-v2.pdf> Acesso em 03/ago/2018.

LIMA, Venício. A. Televisão e política: hipótese sobre a eleição presidencial de 1989. Comunicação \& Política, São Paulo, v. 9, n. 11, p. 29-54, abril/junho 1990.

LORENCINI, Bruno César; GUNDIM, Wagner Wilson Deiró. O recall e sua viabilidade como solução ao Brasil. Revista da Faculdade de Direito do Sul de Minas, 2017, Pouso Alegre, v. 33, n. 1: 373-406, jan. / 2017.

MARCONI, Maria de Andrade; LAKATOS, Eva Maria. Técnicas de pesquisa. 3. Ed. São Paulo: Atlas, 1999.

MOISÉS, José Alvaro. Dilemas da consolidação democrática no Brasil. 1989. Disponível em < http://www.scielo.br/pdf/ln/n16/a03n16.pdf> Acesso em 17/09/2018. 
O`DONNELL, Guillermo. Democracia delegativa? Novos Estudos Cebrap n. 31 - out 91. São Paulo, Brasileira de Ciências, 1991, p. 25-40.

PUFF, Jefferson. O que os juristas que redigiram impeachment de Collor pensam sobre Dilma? Disponível em <https://www.bbc.com/portuguese/noticias/2015/10/151019_juristas_impeachment_jp_tg> Acesso em 29/jan/2019.

SANTOS, Boaventura de Souza; AVRITZER, Leonardo. Para ampliar o cânone democrático. In: SANTOS, Boaventura de Souza (org). Democratizar a democracia: os caminhos da democracia participativa. Rio de Janeiro: Civilização Brasileira, 2002.

SARTORI, Giovanni. Nem presidencialismo nem parlamentarismo.Disponívelem: <http://www.novosestudos.org.br/v1/files/uploads/contents/69/20080625_nem_presidencialismo. pdf>acessoem 23 de fev. de 2017.

SARTORI, Giovanni, Engenharia Constitucional: Como mudam as Constituições. Brasília, Editora Universidade de Brasília, 1996.

SILVA, José Afonso da Silva. Curso de Direito Constitucional Positivo.37a ed. São Paulo: Malheiros, 2014.

SILVA, Luís Virgílio Afonso da. Sistemas eleitorais: tipos, efeitos jurídico-políticos e aplicação ao caso brasileiro. $1^{\text {a }}$ Edição. São Paulo: Malheiros Editores, 1999.

STRECK, Lenio Luiz. DE MORAES, Jose Luis Bolzan. Ciência Política e Teoria do Estado. 8. ed. Porto Alegre: Livraria do Advogado Editora, 2014. 